Supporting Information

for

\title{
$\pi$-Extended Tetraphenylethylene Containing a Dicyanovinyl Group as an Ideal Fluorescence Turn-On and Naked-Eye Color Change Probe for Hydrazine Detection
}

Min Joo Jung, Su Jung Kim, Min Hee Lee*

Department of Chemistry, Sookmyung Women's University, Seoul, 04310, Korea

*Corresponding authors: minheelee@ sookmyung.ac.kr (M. H. Lee)

\section{Table of Contents}

1. Materials and instrumentation

2. UV/Vis absorption and fluorescence methods

3. DLS and FE-SEM measurements

4. Additional Data

5. ${ }^{1} \mathrm{H},{ }^{13} \mathrm{C}$ NMR, and HR-ESI-MS Analyses 


\section{Materials and instrumentation}

All reagents were purchased from Aldrich (Aldrich, St. Louis, MO, USA), Alfa (Alfa, Heysham, LA3 2XY, United Kingdom), or TCI (TCI, Tokyo, Japan) and used without further purification. All solvents were analytical or HPLC grade. Reverse-phase HPLC experiments were conducted using a Shimadzu HPLC (Shimadzu LC 6AD) with a Thermo Scientific Acclain ${ }^{\mathrm{TM}} 120 \mathrm{C} 18(3 \mu \mathrm{m}, 120 \AA$, 2.1 x $150 \mathrm{~mm})$ column for analytical studies. The flow rates for the analytical studies was $0.5 \mathrm{~mL} / \mathrm{min}$. For the mobile phase, buffer A (water with $0.1 \%$ v/v acetic acid) and buffer B (acetonitrile with $0.1 \% \mathrm{v} / \mathrm{v}$ acetic acid) were used to provide the solvent gradient. All fluorescence and UV-Vis absorption spectra were monitored in RF-6000 (Shimadzu Corporation, Kyoto, Kyoto Prefecture, Japan) and UV-2600 (Shimadzu Corporation, Kyoto, Kyoto Prefecture, Japan) spectrophotometer, respectively. ${ }^{1} \mathrm{H}$ and ${ }^{13} \mathrm{C}$ NMR were recorded at Bruker instrument (500 MHz, Bruker Corporation, Billerica, MA, USA). HR-ESI-MS data were obtained using liquid chromatography mass spectrometer (LC/MS) at the Korea Basic Science Institute (KBSI, Seoul) and Sogang University Organic Reaction Research Center.

\section{UV/Vis absorption and fluorescence spectroscopic methods}

Stock solutions of probe $\mathbf{1}$ and compound $\mathbf{2}$ were prepared in HPLC grade acetonitrile (ACN). Various chloride salts of metal ions, such as $\mathrm{Na}^{+}, \mathrm{K}^{+}, \mathrm{Cu}^{+}, \mathrm{Mg}^{2+}, \mathrm{Ca}^{2+}, \mathrm{Fe}^{2+}, \mathrm{Co}^{2+}, \mathrm{Cu}^{2+}, \mathrm{Zn}^{2+}, \mathrm{Fe}^{3+}$, were prepared in distilled water. Various tetrabutylammonium (TBA) salts of anions, such as $\mathrm{OAc}^{-}, \mathrm{ClO}^{4-}, \mathrm{OH}^{-}$, were prepared in distilled water. In the case of redox sensitive agents, $\mathrm{ClO}^{-}$was prepared by dissolving $\mathrm{NaClO}$ in distilled water and $\cdot \mathrm{O}^{2-}$ was prepared by dissolving $\mathrm{KO}_{2}$ in phosphate buffered saline (PBS) $(10 \mathrm{mM}, \mathrm{pH}=7.4) .{ }^{1,2} \mathrm{H}_{2} \mathrm{~S}$ was prepared by dissolving NaHS in PBS $(10 \mathrm{mM}, \mathrm{pH}=7.4)$ solution. Other redox sensitive agents, such as $\mathrm{H}_{2} \mathrm{O}_{2}$, glutathione $(\mathrm{GSH})$, cysteine (Cys), and homocysteine (Hcy), were prepared by dissolving in PBS (10 mM, pH = 7.4) solution. Several amines, including ammonia, butylamine, pyridine, urea, ethylenediamine, hydrazine, were prepared by dissolving in distilled water.

\section{DLS and FE-SEM measurements}

Field emission scanning electron microscopy (FE-SEM) images were conducted on a JEOL JSM-7600F instrument at an accelerating voltage of $10 \mathrm{kV}$. The specimens for SEM images were prepared by depositing several drops of sample solutions onto stubs attached with carbon tapes, then dried under freeze-drying conditions with freeze dryer of Operon for 3 days, then coated with Pt in a 108 auto (Cressington, Magnetron Sputter Coater) for $40 \mathrm{~s}$. The particle sizes and distribution were measured using dynamic light scattering (DLS) with a particle size analyzer (Horiba, SZ-100). Samples for DLS were prepared in $\mathrm{ACN} / \mathrm{H}_{2} \mathrm{O}$ (v/v, 1:9) solution.

\section{Additional Data}

1. Rohde, RD.; Agnew, HD.; Yeo, WS.; Bailey, RC.; Heath, JR. A non-oxidative approach toward chemically and electrochemically functionalizing $\mathrm{Si}(111)$. J. Am. Chem. Soc. 2006, 128, 9518-9525.

2. Mao, Z.; Jiang, H.; Li, Z.; Zhong, C.; Zhang, W.; Liu, Z. An: N -nitrosation reactivity-based two-photon fluorescent probe for the specific in situ detection of nitric oxide. Chem. Sci. 2017, 8, 4533-4538. 

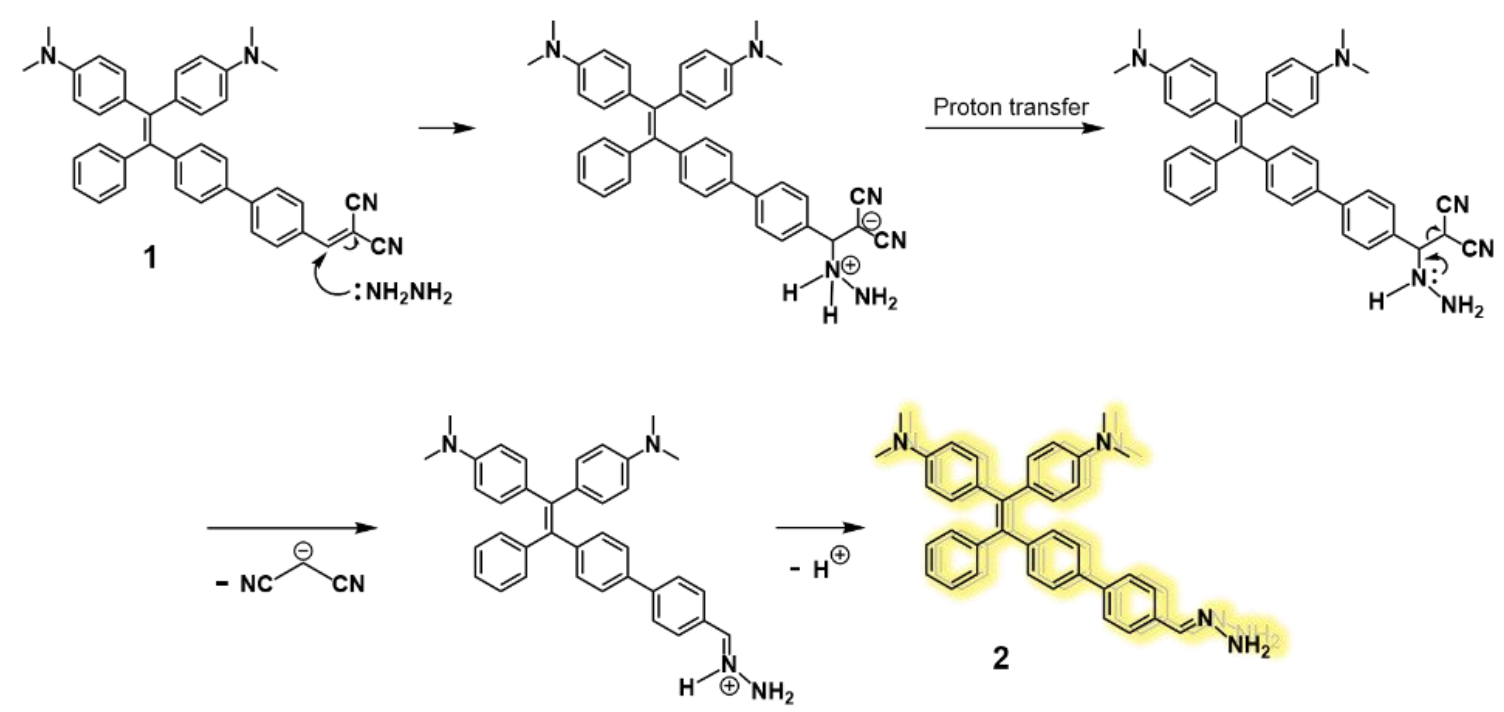

Scheme S1. Proposed reaction mechanism of probe 1 with hydrazine.

a)

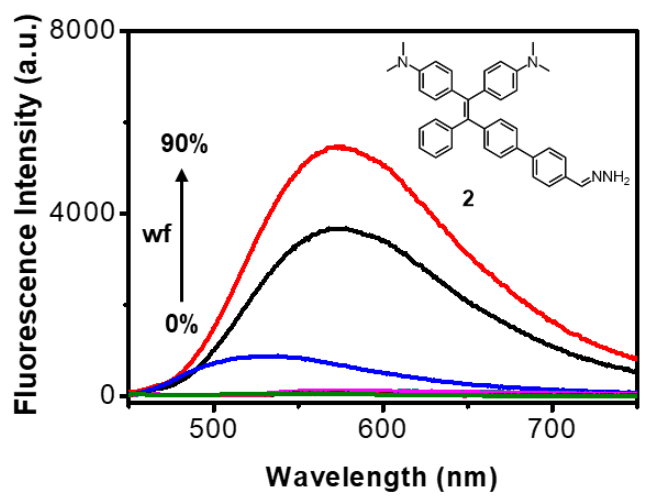

b)

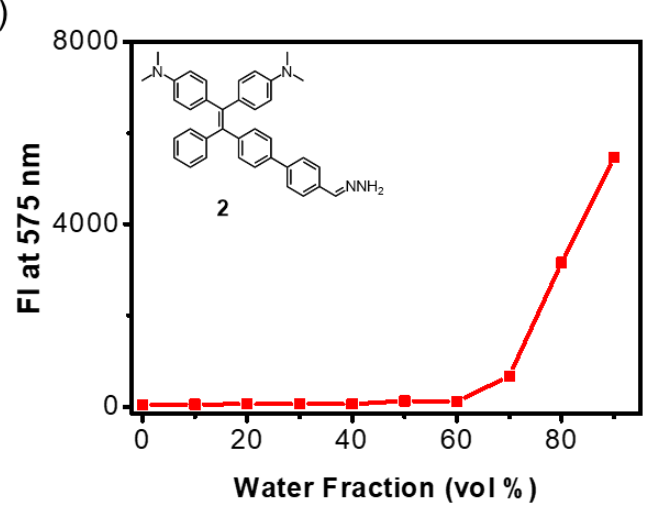

Figure S1. (a) Fluorescence spectra of $2(10 \mu \mathrm{M})$ in $\mathrm{ACN} / \mathrm{H}_{2} \mathrm{O}$ mixture with different water fractions $(0-90 \%)$. (b) A plot of FI at $575 \mathrm{~nm} v s$. water fraction. Excitation wavelength was $400 \mathrm{~nm}$. 


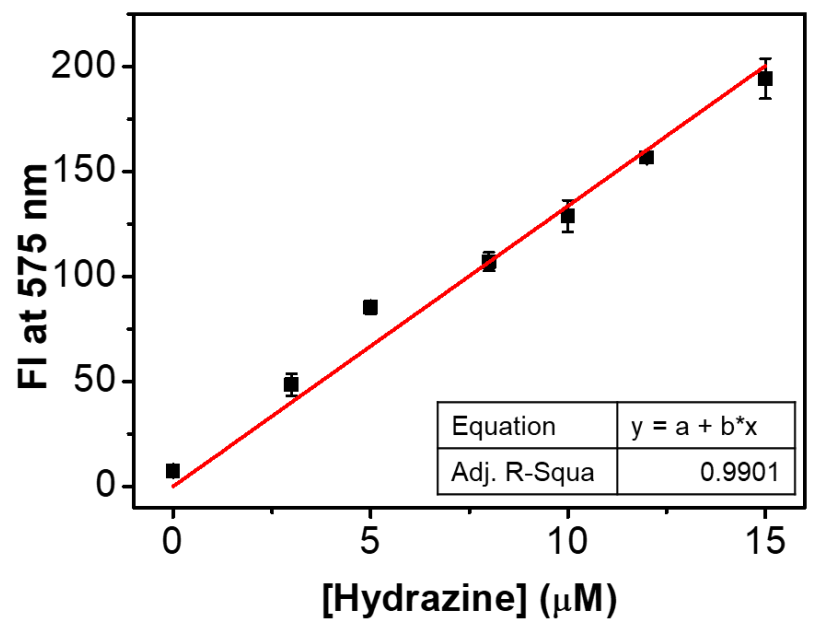

Figure S2. A plot of fluorescence intensity at $575 \mathrm{~nm}$ of $\mathbf{1}(10 \mu \mathrm{M}) v s$. [Hydrazine]. The limit of detection (LOD) of 1 for hydrazine turned out to be $0.11 \mu \mathrm{M}$. LOD was obtained based on $3 \sigma / \mathrm{k}$ equation, where $\sigma$ and $\mathrm{k}$ indicated standard deviation of blank measurement $(\sigma=0.5041)$ and slope $(\mathrm{k}=13.3607)$, respectively. All data were acquired $10 \mathrm{~min}$ of incubation at room temperature. Excitation wavelength was $400 \mathrm{~nm}$.

a)

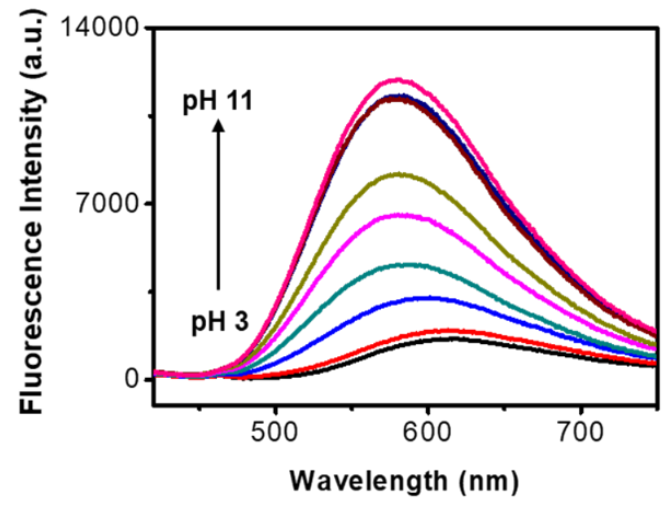

b)

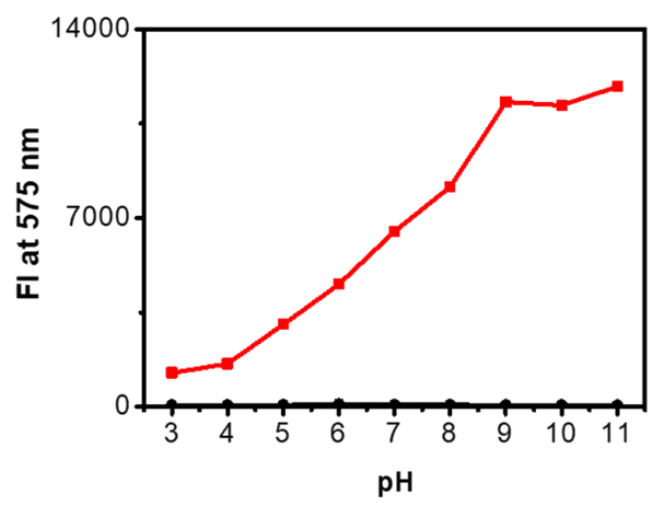

Figure S3. Fluorescence changes of $\mathbf{1}(10 \mu \mathrm{M})$ to 10 equiv. of hydrazine in $\mathrm{ACN} / \mathrm{H}_{2} \mathrm{O}(1: 9, \mathrm{v} / \mathrm{v})$ at different $\mathrm{pH}$ values of 3-11. All data were obtained $10 \mathrm{~min}$ of incubation at room temperature. Excitation wavelength was 400 nm. 


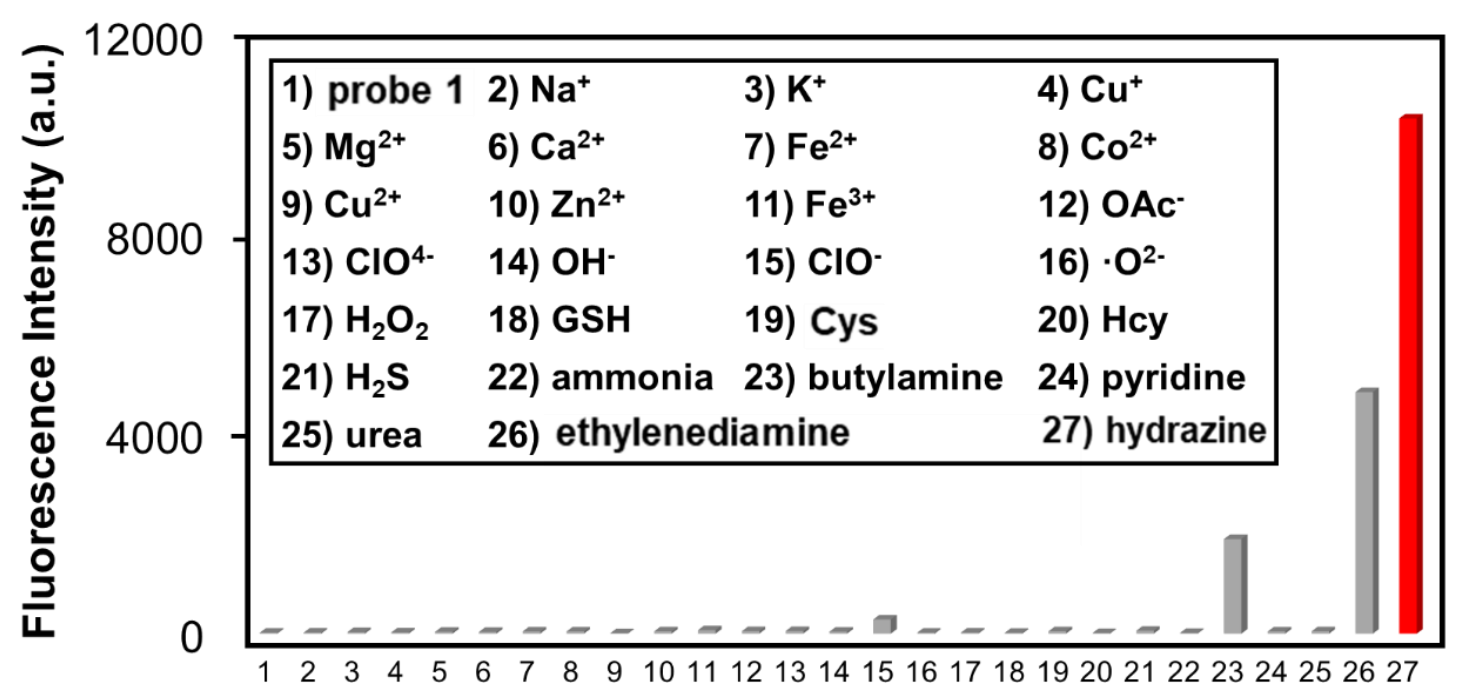

Figure S4. Fluorescence responses of $\mathbf{1}(10 \mu \mathrm{M})$ to hydrazine and other species (10 equiv, respectively). All data were obtained in $\mathrm{ACN} / \mathrm{H}_{2} \mathrm{O}(1: 9, \mathrm{v} / \mathrm{v})$ after $10 \mathrm{~min}$ of incubation at room temperature. Excitation wavelength was $400 \mathrm{~nm}$.

5. ${ }^{1} \mathrm{H},{ }^{13} \mathrm{C}$ NMR, and HR-ESI-MS Analyses

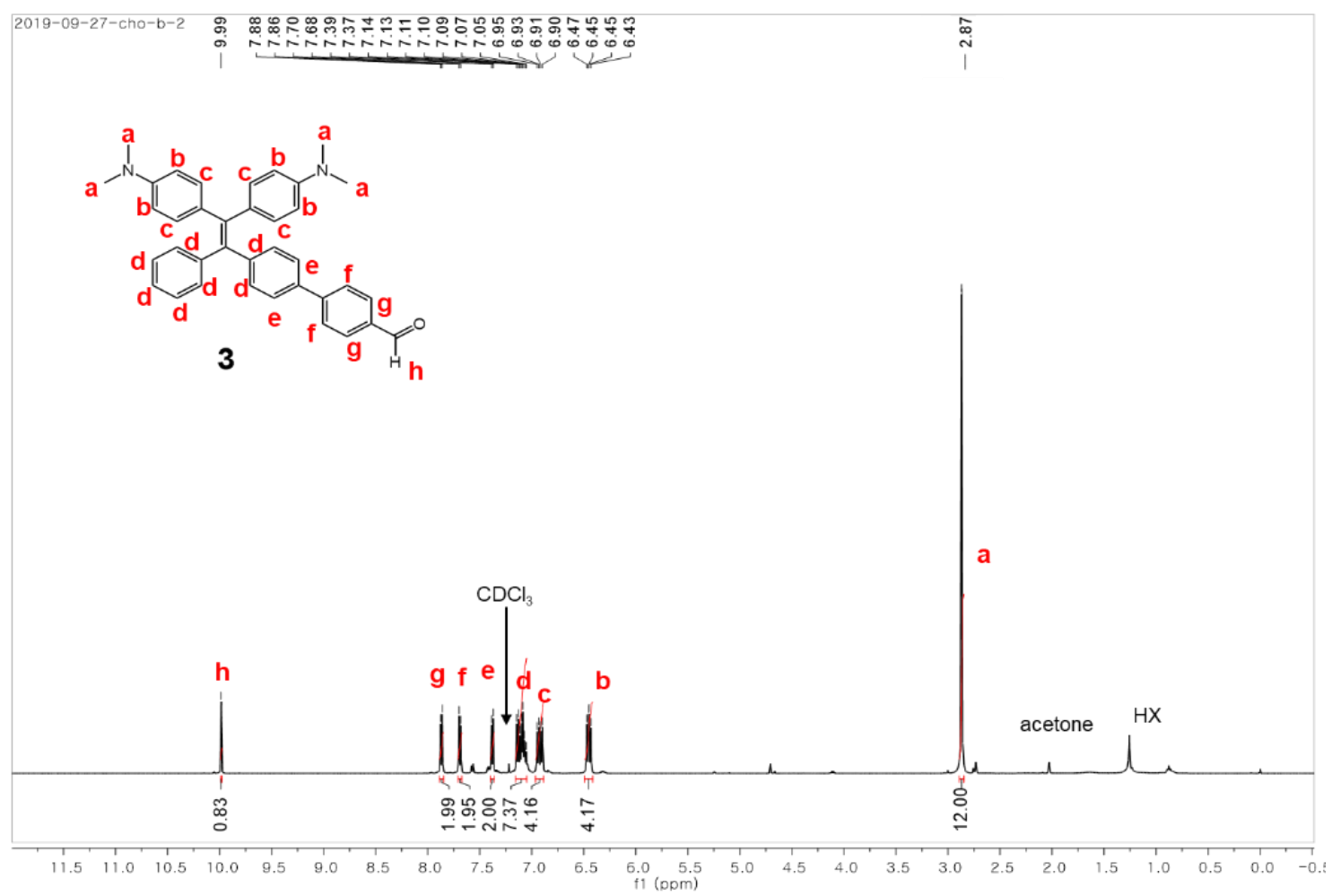

Figure S5. The ${ }^{1} \mathrm{H}$ NMR spectrum of 3 . 


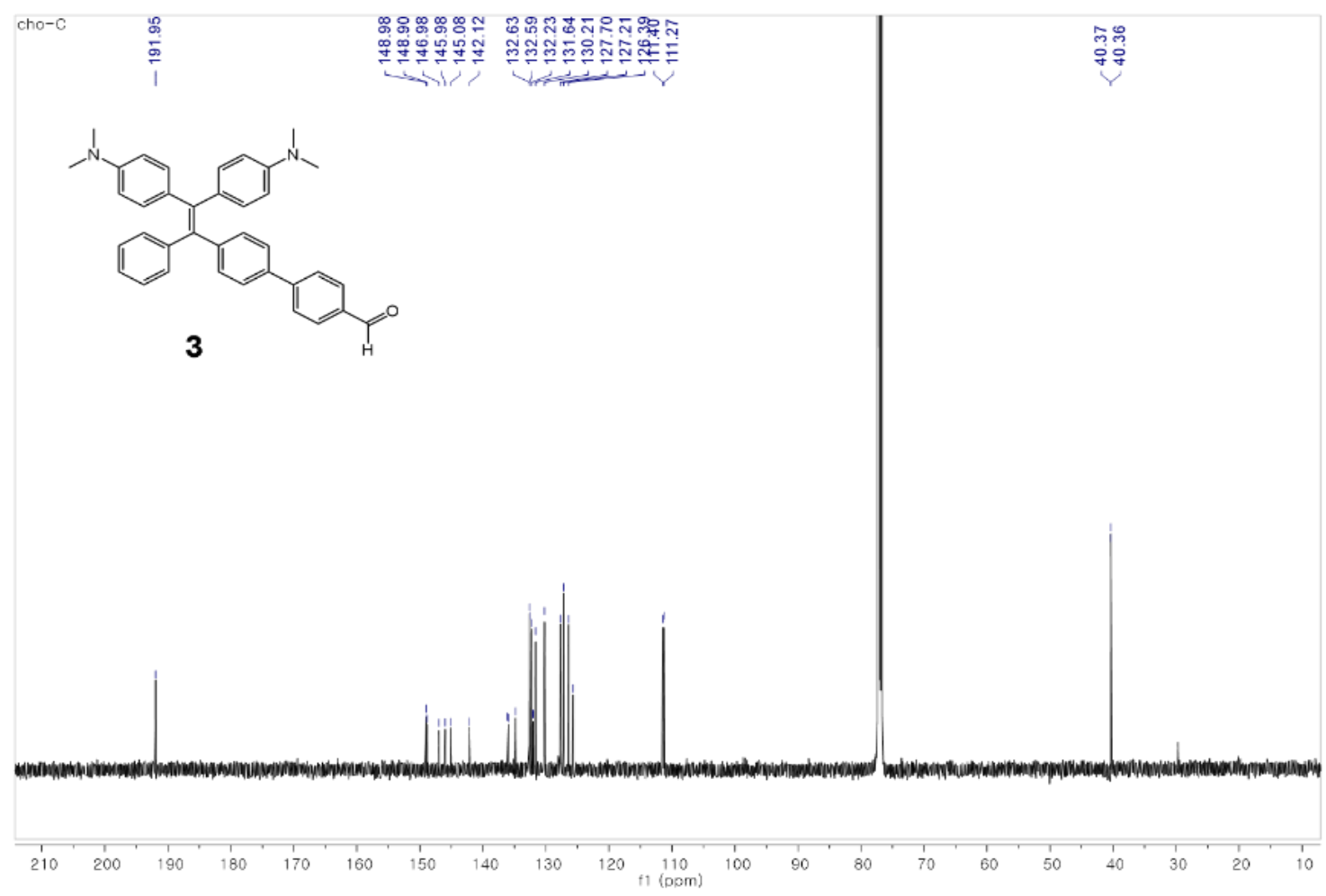

Figure S6. The ${ }^{13} \mathrm{C}$ NMR spectrum of $\mathbf{3}$.

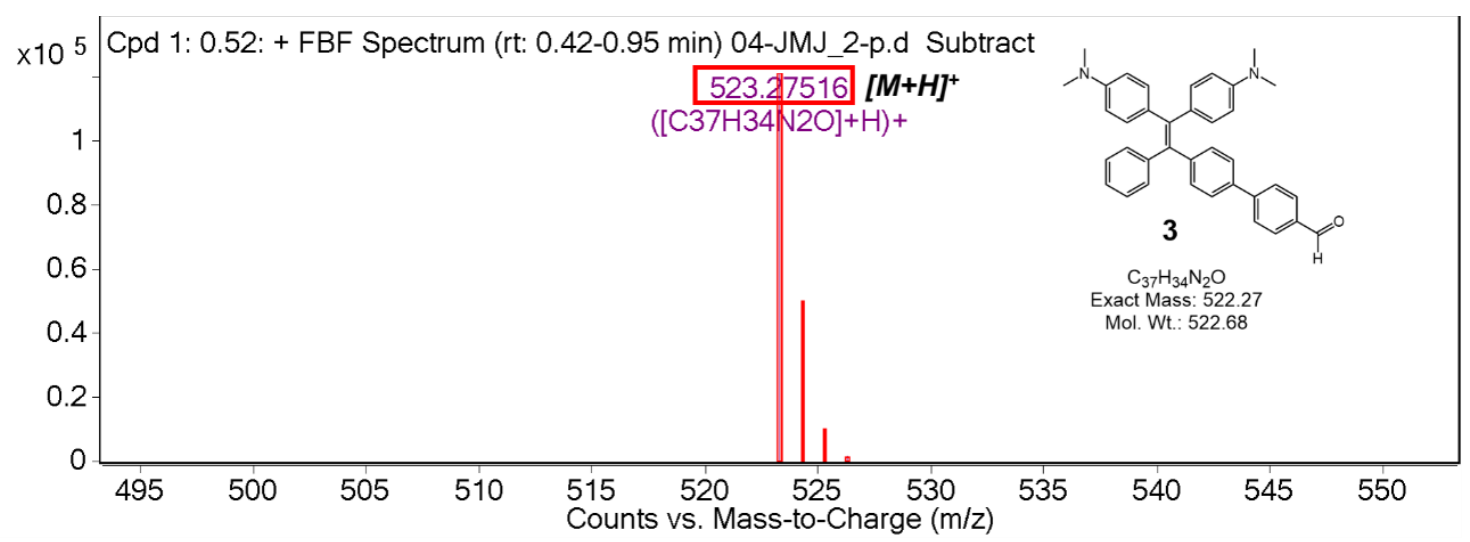

Figure S7. HR-ESI-MS spectrum of 3. 


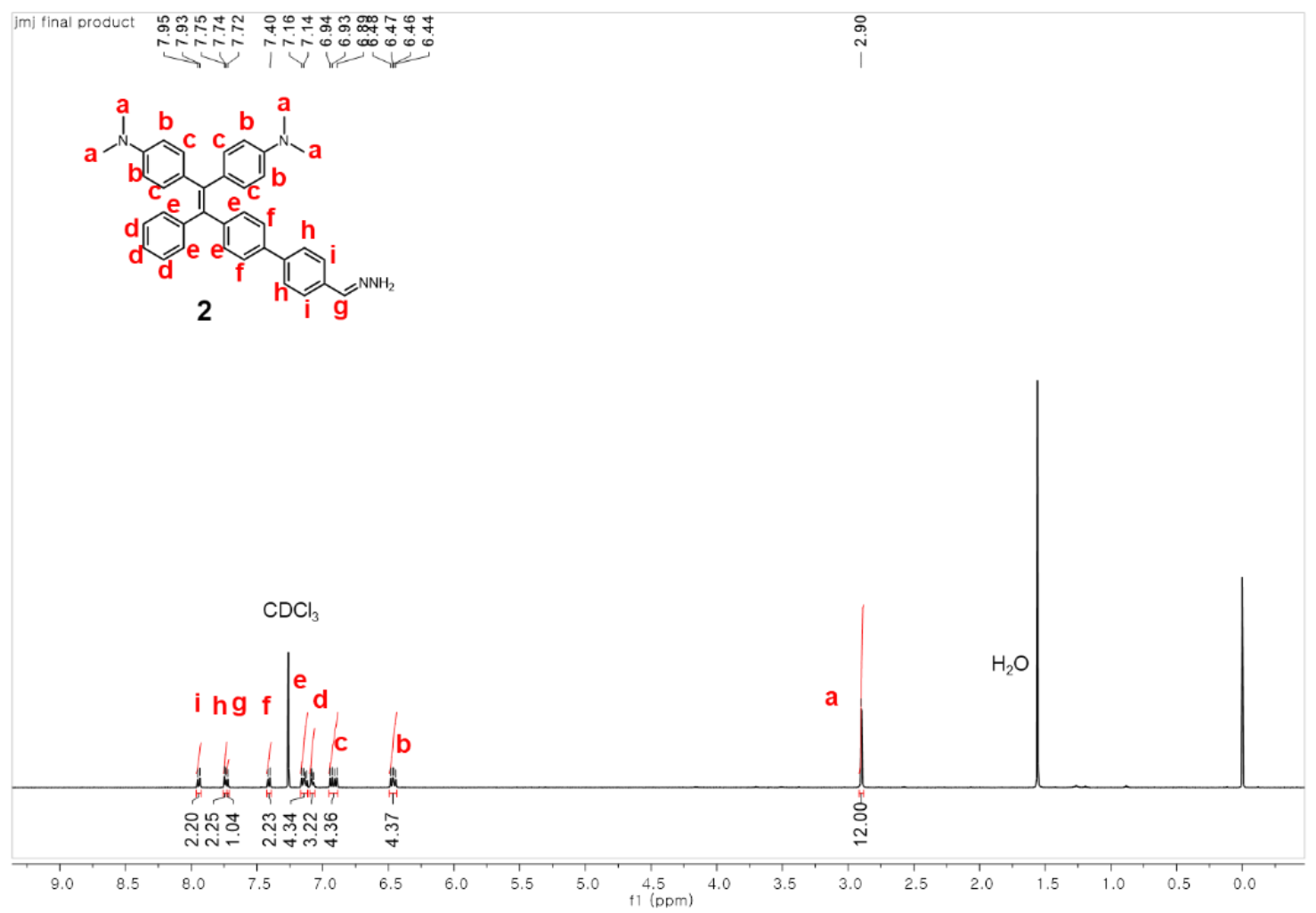

Figure S8. The ${ }^{1} \mathrm{H}$ NMR spectrum of 2 .

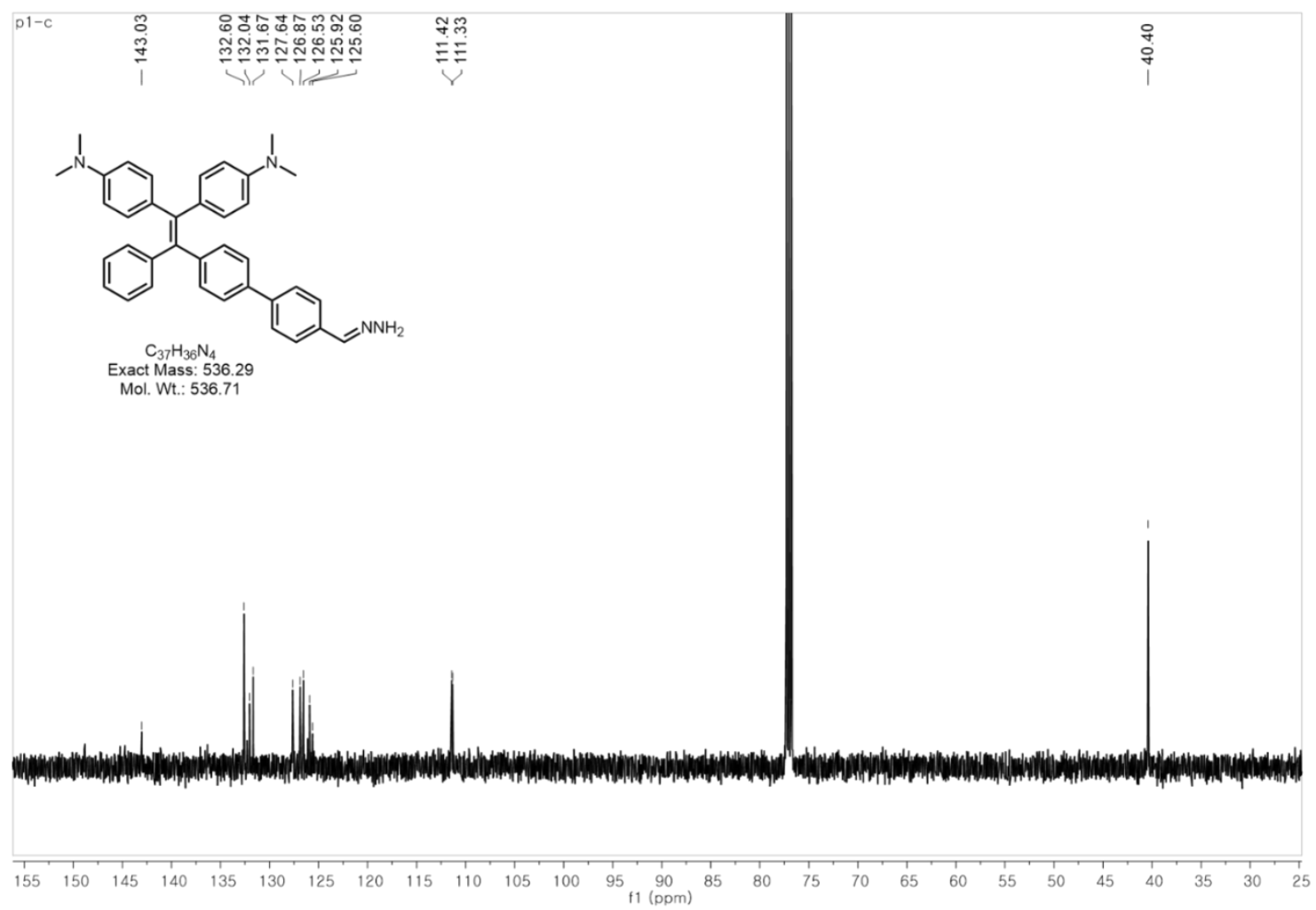

Figure S9. The ${ }^{13} \mathrm{C}$ NMR spectrum of 2 .

ST 


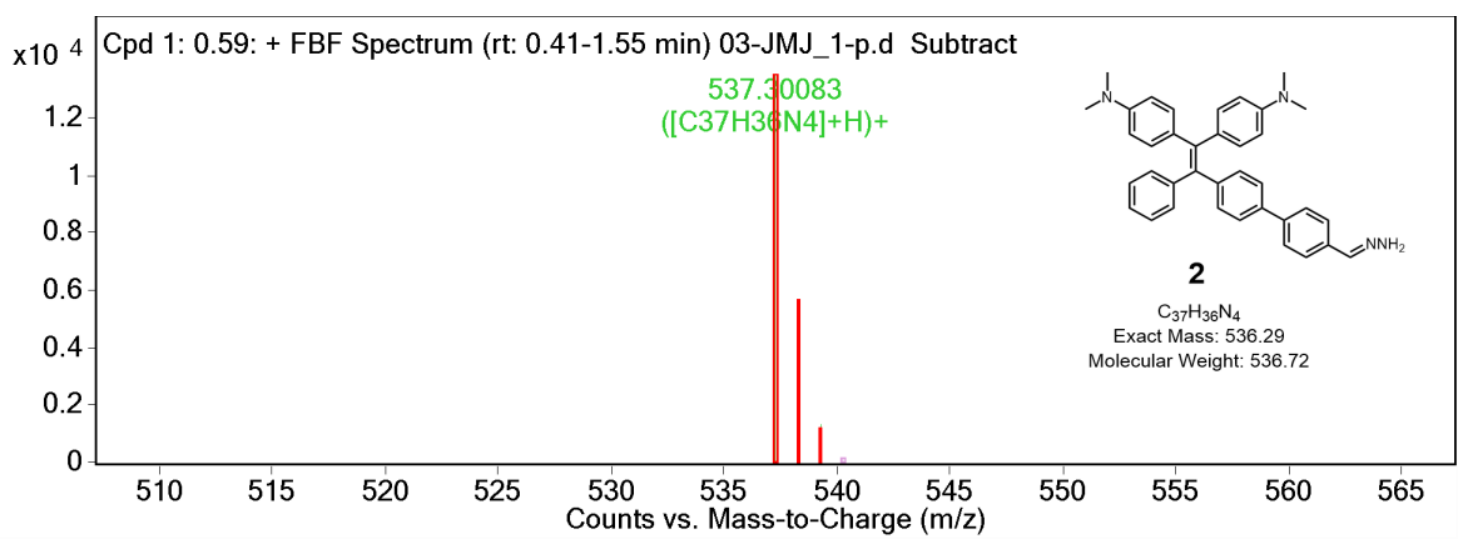

Figure S10. HR-ESI-MS spectrum of 2.

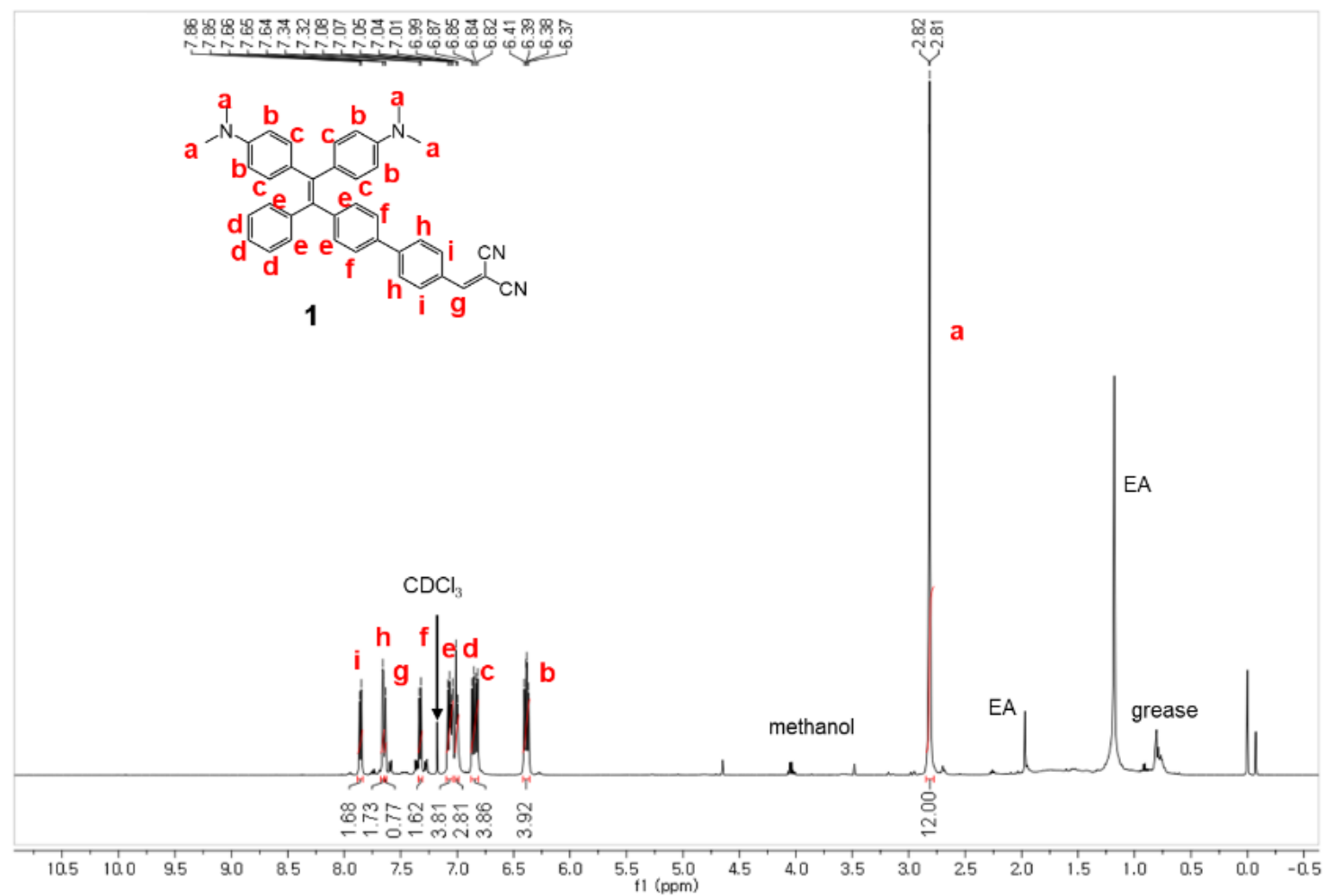

Figure S11. The ${ }^{1} \mathrm{H}$ NMR spectrum of $\mathbf{1}$. 


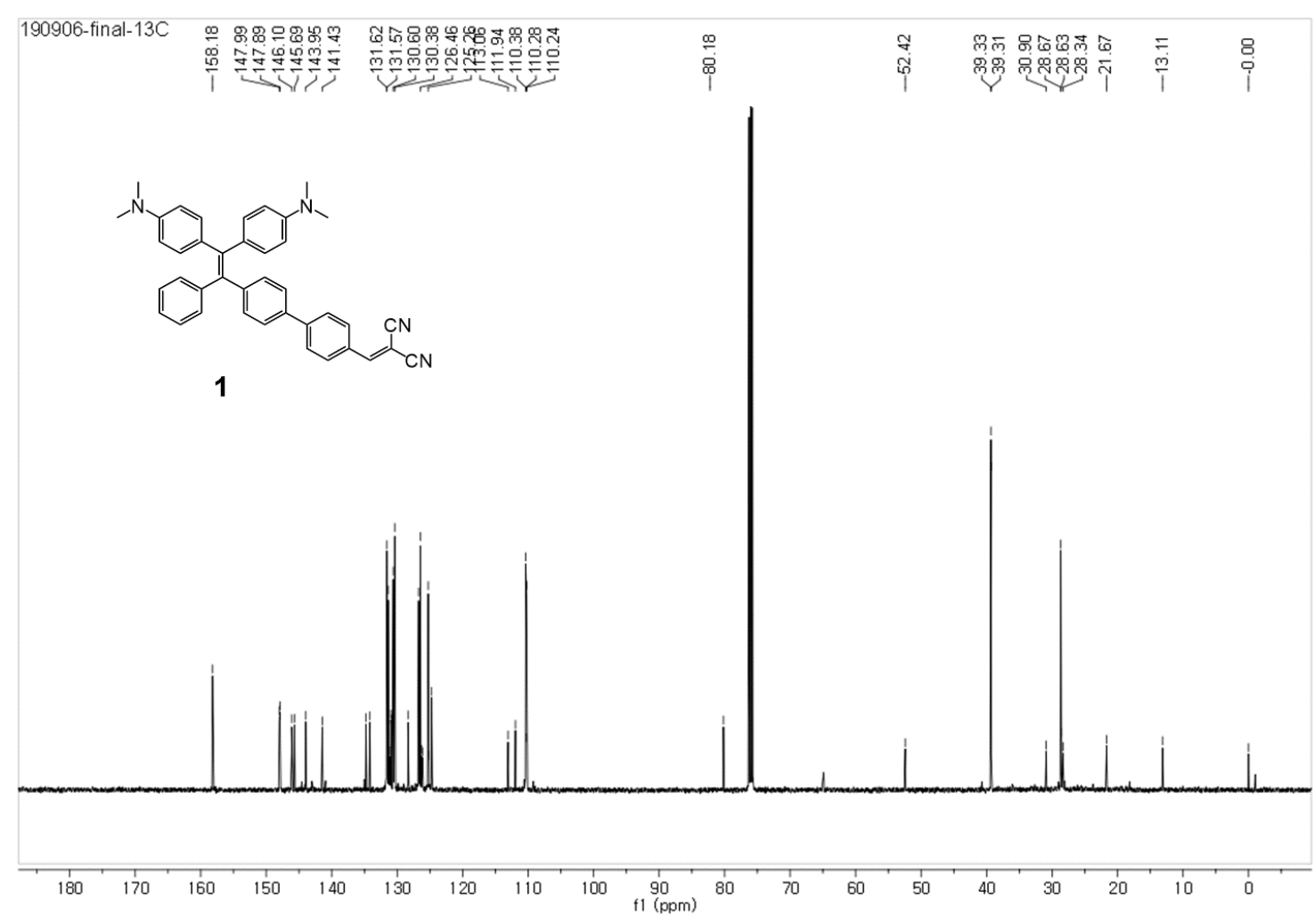

Figure S12. The ${ }^{13} \mathrm{C}$ NMR spectrum of $\mathbf{1}$.

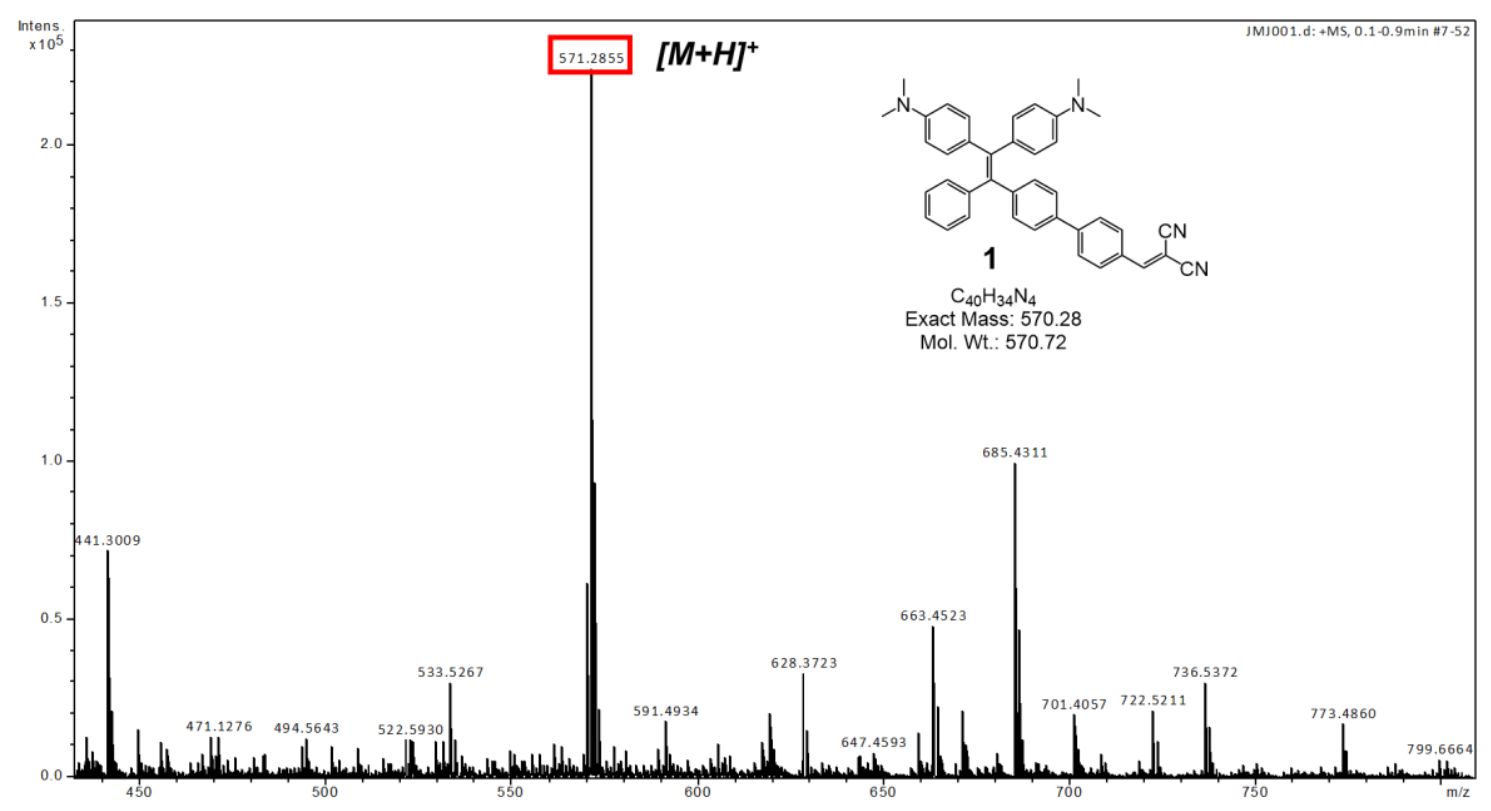

Figure S13. HR-ESI-MS spectrum of 1. 